\title{
Refrações do conceito de filme de cinema na obra de Rogério Sganzerla
}

\author{
Irene de Araújo Machado \\ Doutora; Universidade de São Paulo, SP, Brasil. \\ irenear@usp.br

\section{Daniel Felipe Espinola Lima Fonseca} \\ Mestre; Universidade de São Paulo, SP, Brasil. \\ danielfelipe@usp.br
}

\begin{abstract}
Resumo
O artigo examina o pensamento crítico-criativo do cineasta Rogério Sganzerla (1946-2004), cruzando sua produção teórica com procedimentos construtivos de O Bandido da Luz Vermelha (1968), sua estreia na direção de longas-metragens. Trabalha-se com a hipótese de que o olhar para o sistema de sua produção revela, para além de uma aplicação de suas formulações críticas em sua obra fílmica, o modo como seu pensamento se configura de modo a considerar a dialogia - quer seja num nível da tessitura das relações críticas e metalinguísticas propostas, quer seja no âmbito da diegese - como elemento implícito na organização de um sistema teórico-crítico-criativo.
\end{abstract}

\section{Palavras-chave}

Rogério Sganzerla. Cinema brasileiro. Crítica. Dialogia. Metalinguagem.

\section{Introdução}

Poucos são os filmes que nascem da necessidade que tem o cineasta de dar um corpo audiovisual a um pensamento sobre cinema. Mais restrito ainda é o número de cineastas que transforma o pensamento em realizações que revertem o ciclo produtivo em exercício crítico de modo a reconstruir pensamento e realização numa metalinguagem crítica. Segundo a perspectiva crítico-analítica do presente ensaio, Rogério Sganzerla foi um desses 
cineastas que legou uma obra cinematográfica cuja noção de «filmecos» ${ }^{1}$ seria não apenas chave conceitual como também a definição de um modo de fazer cinema segundo processos criativos em filmes que deixariam suas marcas na cinematografia da segunda metade do século XX, contribuindo para a constituição do cinema brasileiro moderno (XAVIER, 2001). O objetivo do ensaio é, portanto, examinar as bases da metalinguagem crítica de Sganzerla observando a coerência de seu sistema teórico, de seu processo criativo e de suas contradições que, aliás, são inerentes a todo pensamento que busca a crítica, inclusive em sua própria configuração.

Nesse sentido, uma investigação com tais intuitos pode trabalhar a relação entre crítica e criação em, pelo menos, três níveis. 0 primeiro, da relação de correspondência, isto é, o exame da relação entre hipóteses e exercícios de leitura crítica das cinematografias que lhe foram contemporâneas para ulterior publicação nas páginas dos jornais como fontes de um repertório de criação. 0 segundo, da tradução, ou seja, o modo como o texto artísticofílmico sganzerliano não apenas "adapta" ou "transpõe" ideias de um meio a outro, como também estabelece uma relação de continuidade com a formulação teórica, e torna o espaço criativo um terreno fértil para a composição de novas reflexões, agora em forma estética, de uma poética ou uma poiesis que se situe em torno do mesmo ideário. E, por fim, um terceiro nível, que considere também informações implícitas não apenas nos textos criativos como nas próprias críticas - aqui, um deslocamento do conceito de "teoria implícita" proposto por Jacques Aumont (2012), que se referia àquela inerente especificamente às produções cinematográficas -, ou seja, que se situe para além do que foi explicitamente formulado. Trata-se de uma prática que caminha em direção à tendência que ajudou a fomentar o trabalho produtivo do ensaio fílmico que se consolida cada vez mais em torno do filme documentário. Em Sganzerla o caráter ensaístico consolida-se em termos de procedimento criativo, ou de um modo de ver o mundo e transformá-lo em escrita audiovisual. É esse terceiro nível de complexidade na correlação entre crítica e criação que será examinado no presente texto - o que, por si só, não desconsidera os demais em seu modus operandi.

Neste direcionamento, propõe-se desenvolver o exercício da metalinguagem crítica da qual falamos anteriormente. Para isso convoca-se a perspectiva de um raciocínio analítico de natureza dialógica que tanto orienta a análise quanto qualifica o pensamento

\footnotetext{
1 «Filmecos» é o modo como Sganzerla definiu sua poiesis - base experimental do «filme de cinema». Em entrevista ao jornal 0 Pasquim em 1970, Helena Ignez lembra que uma das melhores sínteses de seu cinema se concentra na afirmação: "Eu faço os maiores filmecos do Brasil." Trata-se de valorizar o vínculo de seus filmes com a natureza e a vocação subdesenvolvida de sua produção que se reverte em repertório estético-crítico de inovação. (O PASQUIM, 1970).
} 
crítico do cineasta e de seus filmes tramados nos entrecruzamentos de cinematografias. Dialogia remete, sem dúvida, às formulações teorizadas por Mikhail Bakhtin e seu círculo intelectual - mesmo que o cineasta não tenha, é importante frisar, inserido propositivamente o pensamento bakhtiniano no centro de suas preocupações, como o fez, entre outros, com o filósofo Jean-Paul Sartre e com o literato Alain Robbe-Grillet. A dialogia que se mobiliza aqui diz respeito ao modo de construção de uma perspectiva crítica que não se contenta em representar o mundo. Trata-se de registrar, na superfície da película fílmica, não um reflexo de situações, mas sim sua refração como atividade sígnica de todo processo dialógico que emerge do tensionamento de ideias que movimentam ideologias. Assim, a abordagem dialógica apreendida em Sganzerla é entendida como corolário de uma inserção do realizador num universo ideológico que considera e pensa as condições da vida no vasto campo de um sistema produtivo, de onde não se elimina o advento técnico no campo artístico, nem a presença dos meios na vida cotidiana. Note-se, nesse sentido, o constante aparecimento em suas obras da apropriação, integração e tradução de materiais de arquivo e da consequente recontextualização nas dinâmicas de intertextualidades.

Se o universo conceitual produzido em suas críticas - fundado em formulações como a câmera cínica, o herói fechado, os cinemas do corpo e da alma - é capaz de dar ao trabalho do cineasta um arcabouço revelador de muitos de seus principais intuitos, o viés dialógico, por sua vez, também torna próximas obras aparentemente tão distintas quanto $A$ Mulher de Todos (1969) e Sem Essa Aranha (1970); Abismu (1977) e Nem Tudo é Verdade (1986). Em sua crítica inicial, produzida nos anos 1960 em 0 Estado de S. Paulo, a dialogia do futuro realizador aparece na proposição de teias relacionais na forma de diagramas que revisam a história do cinema. Emerge uma crítica que não só alcança o cinema moderno pelos traços inovadores de sua linguagem como também é capaz de transformá-los em procedimentos construtivos da renovação de linguagem, como se pode ler no texto de um dos diagramas inseridos entre os capítulos do livro que reúne parte de sua produção escrita (figura 1)².

\footnotetext{
2 Em Sganzerla (2001), no encarte entre as páginas 80 e 81: Humberto Mauro (no centro da foto), ao lado do grande iluminador Edgar Brasil, filmando a inauguração da Usina Ituaerê, em Minas Gerais, 1926. Para o autor de $O$ Canto da Saudade, 1951, "cinema lembra cachoeira, as águas não param nunca; e têm força, beleza, continuidade, uma cascata de imagens se sucedendo". Aproximando-se da natureza com cuidado, Humberto Mauro escondia sua câmera geralmente atrás de uma bananeira, disposto a captar o cheiro do mato, com um ritmo lento, bem brasileiro. Sua melodia harmoniosa, verdadeira métrica sistêmica, quase uma síntese orgânica, compõe-se com vastidões de pensamento.
} 
Figura 1 - Fotografia de Humberto Mauro e Edgar Brasil.

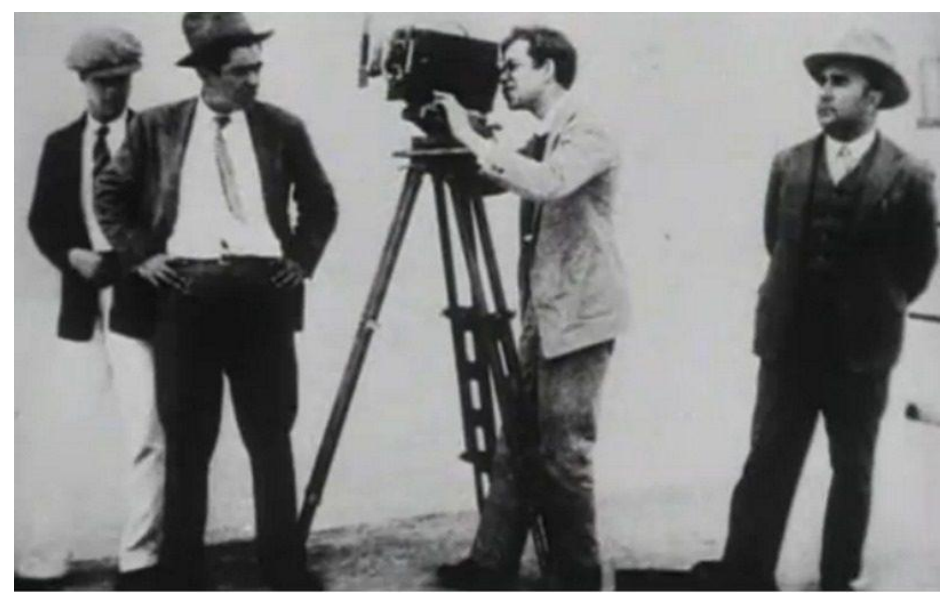

Fonte: foto reproduzida a partir de https://abcine.org.br/site/edgar-brasil-o-patrono-dos-diretoresde-fotografia-brasileiros/. Acesso em 30 abr. 2019.

Se nesse diagrama se sobressai a análise do processo construtivo da linguagem na realização, no capítulo dedicado à gênese de sua explanação da dicotomia entre os cinemas do corpo e da alma, o fundamento de seu raciocínio surge da intertextualidade subversiva em relação à Robbe-Grillet, quando o crítico se apropria da terminologia de inspiração sartreana usada por Robbe-Grillet em sua obra literária. Sganzerla serve-se de tal procedimento para discutir um cinema corporal, ontologicamente considerado como arte da visibilidade, contrário à interiorização, que deveria, para ele, ser exclusivamente matéria literária. 0 cinema do corpo cria um contraponto com a prática literária de Robbe-Grillet naquilo que ela desenvolve como literatura de inspiração cinematográfica.

No início de sua atividade de cineasta - dos primeiros curtas-metragens até $O$ Bandido da Luz Vermelha e A Mulher de Todos - a dialogia se constrói na permanência da conversa com a história do cinema iniciado nos painéis - apropriadamente descrita no Manifesto Cinema Fora da Lei. No tecido de colagens e referências das camadas de sua montagem vertical, na polifonia das cidades, com seus signos sobrepostos em meios diversos, na espacialidade registrada pela câmera, que acompanha a perambulação dos personagens - em tudo se observa um exercício de metalinguagem que se alimenta em alta valência de produções da indústria cultural. Em outro momento, quando da criação da produtora Belair (1970) até Abismu (1977), o diálogo privilegia o acontecimento singular da filmagem enquanto processo, com especial ênfase para a relação de tensão entre os atores e os aparatos que os registram; entre quem (e o que) filma e quem (ou o que) é filmado, transgredindo os limites da experimentação de modo a tensionar a trama de sua 
metalinguagem. Tal procedimento torna-se mais evidente na exploração do precário como elemento de linguagem, que agride certo "bom gosto" afeito à linearidade narrativa.

A partir dos anos 1980, em um encaminhamento que já se insinuava pelo menos desde a presença de Jimi Hendrix em Abismu, Sganzerla constrói uma obra que se volta às trajetórias de artistas de variados campos, em projetos altamente obsessivos que reconstroem trajetórias individuais por meio, entre outras características, do arquivo apropriado, agregando camadas à história. 0 arquivo, o indivíduo, o histórico e a ideia de narrativas entre narrativas tanto definem as principais preocupações do criador até o final de sua carreira quanto delineiam um projeto construtivo de experimentação como exercício metacrítico não alinhado a uma fórmula, como se espera examinar na sequência.

O olhar para a dialogia permite alcançar novos elementos, estabelecer novas relações, ampliar o contexto indagativo para além da correspondência entre seu trabalho crítico e criativo. Trata-se de um campo de possibilidades que evidenciam a transformação coerente do pensamento sganzerliano, estabelecendo pontos conectivos da obra com o cinema comprometido com intervenções nas cinematografias de seu tempo. Para isso, propõe-se, neste texto, iniciar um exame da natureza dialógica inerente ao sistema críticocriativo de Sganzerla a partir de $O$ Bandido da Luz Vermelha - marco de uma escalada que contribui para a expansão do cinema moderno no Brasil.

\section{Trama dialógica como princípio construtivo audiovisual}

Os créditos iniciais de $O$ Bandido da Luz Vermelha já trazem elementos não só para uma observação da relação entre seu pensamento crítico e sua produção criativa como também para a emergência de ideias que evidenciam uma visão dialógica de mundo. De início, uma provocação que parece uma ambiguidade a evocar certa polissemia, quando surge nos créditos a epígrafe: «Filme de cinema». De imediato, a epígrafe (figura 2) parece indicar um pensamento que trataria das tensões entre o que se pode considerar cinema e o que não entra para essa categoria. Algo que numa leitura teórica talvez marcasse o contraste de um cinema situado num plano elevado já consagrado e um outro, situado num plano inferior. Contudo, a ambiguidade tende a aumentar uma vez que não se sabe ao certo o que o cineasta situa em cada plano. Talvez quisesse tão somente remeter para o próprio advento do cinematógrafo como criador desse tensionamento que, sendo resultado da técnica, nunca 
deixou de frequentar os lugarejos da assim chamada baixa cultura. Afinal, se trata de um filme que se alimenta do imaginário acerca de um bandido cuja performance nos crimes praticados deixaram marcas na vida cultural da cidade de São Paulo nos anos de 1960, como os jornais populares não deixavam de publicar. Logo, existe muito a se dizer da epígrafe sganzerliana em $O$ Bandido da Luz Vermelha, sendo a própria riqueza da expressão uma forma de propor um olhar cuidadoso para o que à primeira vista aparenta ser vulgar.

Figura 2 - Fotograma de 0 Bandido da Luz Vermelha aos 47 segundos. Direção: Rogério Sganzerla.

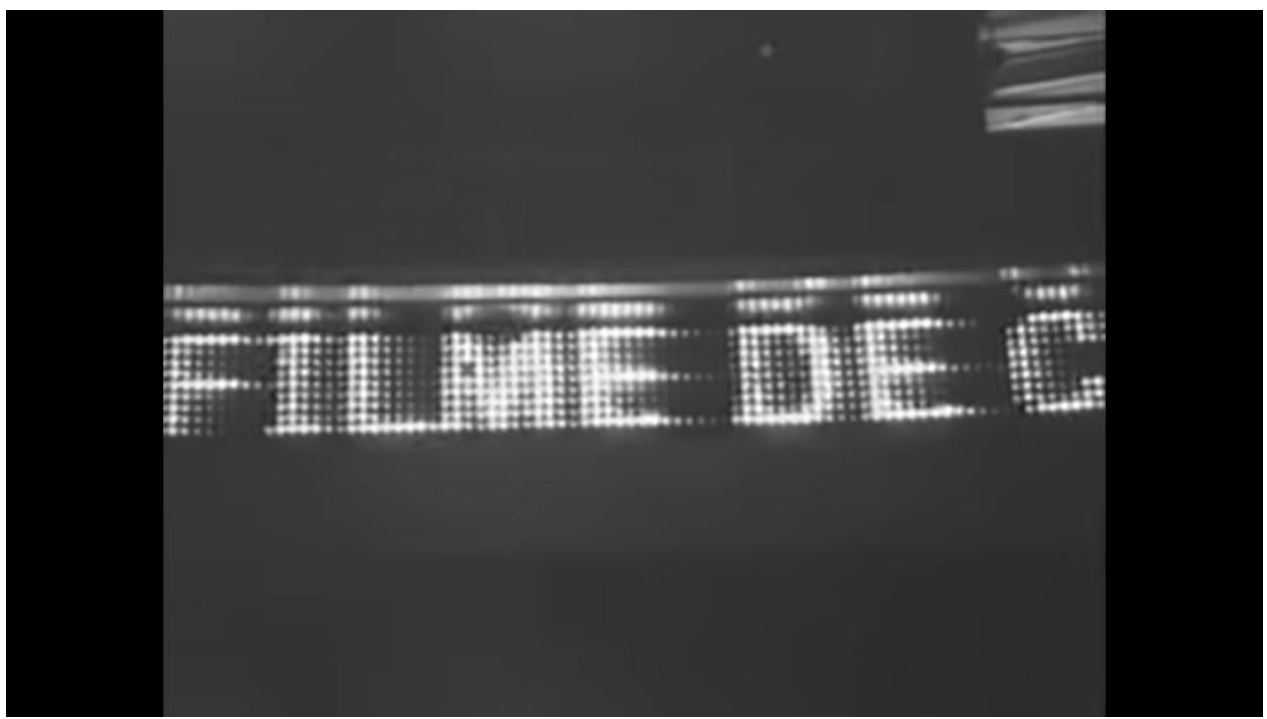

Fonte: reprodução de 0 Bandido da Luz Vermelha (1968).

Em primeiro lugar, há que se notar a transformação da frase da epígrafe em painel eletrônico que compõe com os outros letreiros luminosos as frases que emergem ao longo do filme e, em cada uma de suas aparições, com um sentido distinto. Temos aqui uma entrada para a trama dialógica criada por Sganzerla para uma dramaturgia especificamente audiovisual: aquela que confere corporeidade ao universo sensorial e sensível registrado em película de som e de imagem visual. Para elucidar tal criação há que se reportar à concepção de Sganzerla que distingue entre cinema da alma e cinema do corpo, forjada no contexto do pipocar de cinemas novos dos anos 1960. Ao primeiro, o crítico reserva a noção de um cinema que possui, em sua leitura, a pretensão de "elevar" a arte do movimento e do som à altura da construção do drama psicológico de personagens de páginas literárias - algo que, no contexto fílmico, acarretaria numa vivência interior impossível de ser registrada pelas câmeras. Quanto ao segundo, trata-se de um cinema que se compreende enquanto arte do 
visível e do audível - do aparente, em suma -, cujo único pecado, para o futuro realizador, seria o de não possuir a mesma pretensão da vertente da alma de buscar por uma densidade, ainda que distinta da de seus antípodas na medida em que, pela via do corpo, o cinematográfico não se restringiria a uma cópia barata e deslocada da literatura. 0 herói desse cinema também seria indevassável; contudo, seria construído a partir de suas características físicas em detrimento da psicologia. Nesse sentido, se o cognome "luz vermelha" remete à lanterna usada pelo bandido nos assaltos após cortar fios elétricos, também são luzes os pontos dos painéis eletrônicos que o display do jornal $O$ Estado de $S$. Paulo noticiava os crimes. Luz como matéria, energia, nome, signo luminoso de lusco-fusco que é o personagem de corpo-e-alma.

Lendo a frase "filme de cinema" no contexto de outras como, por exemplo, "faroeste do terceiro mundo", cujos personagens, frisa-se, não pertencem "ao mundo, mas ao terceiro mundo", vemos abrir um diálogo de contrapontos que se revela na inversão cronotópica que vincula o cinema ao "faroeste do terceiro mundo". Sabemos que a tela de cinema consagrou a expansão do espaço geográfico do velho oeste norte-americano do século XIX como o cronotopo de um gênero fílmico: o western em que figuram cowboys vitoriosos. Em 0 bandido, a aventura não é nem heroica, nem vitoriosa, mas somente selvagem. Sem nenhum mito; sem alma; mas apenas corpo como ponto de partida. A epígrafe, portanto, quando contraposta aos intuitos do Sganzerla crítico, revela a ênfase sganzerliana contra uma cinematografia que, em sua leitura, seria incapaz de explorar o potencial físico da chamada sétima arte, na medida em que enfatizaria no cerne de sua criação aspectos psicológicos, sociológicos e literários na composição das obras. No "filme de cinema", a metalinguagem crítica se apresenta na forma de posicionamento e embate estético. Há, portanto, a continuação evidente do posicionamento e do embate iniciado nas páginas dos jornais, agora em forma artística.

A própria atuação de Sganzerla como cineasta criador e crítico convida a uma imersão dialógica em sua obra. E é já como criador que Sganzerla escreve durante as filmagens de $O$ Bandido um manifesto, Cinema Fora da Lei, em que evidencia, por conta própria, o modo como a obra que estava a filmar se põe em relação com a cultura cinematográfica. $O$ texto em questão é uma grande declaração de influências que o cineasta reverte dialogicamente em procedimentos na composição de seus filmes. Com relação à análise dos painéis luminosos analisados anteriormente ele afirma em um dos segmentos de seu manifesto: 
Meu filme é um far-west sobre o III Mundo. Isto é, fusão e mixagem de vários gêneros. Fiz um filme-soma; um far-west, mas também musical, documentário, policial, comédia (ou chanchada?) e ficção científica. Do documentário, a sinceridade (Rossellini); do policial, a violência (Fuller); da comédia, o ritmo anárquico (Sennett, Keaton); do western, a simplificação brutal dos conflitos (Mann). (SGANZERLA, 2005, p. 39).

É notório, nesse excerto inicial do manifesto, o procedimento declarado de dialogia em sua atividade criadora, bem como a afinidade de sua leitura acerca dos gêneros no que se diz respeito a formulações bakhtinianas. Para o teórico russo, um gênero discursivo se refere a um tipo de enunciado possuidor de uma estabilidade relativa. Cada enunciado, para ele, se coloca em relação a outro(s) enunciado(s), na medida em que se trata de "um elo na corrente complexamente organizada de enunciados" (BAKHTIN, 2016, p. 26). Ainda que cada texto pressuponha "um sistema universalmente aceito", escreve Bakhtin, "não há e nem pode haver textos puros" (2016, p. 74). Falar sobre gêneros, portanto, implica na consideração do processo vivo de transformação dos códigos, logo, em considerar que seu repertório "cresce e se diferencia à medida em que tal campo se desenvolve e ganha complexidade" (2016, p. 12). A ideia de um "filme-soma", produtor de "fusão e mixagem de vários gêneros", evidencia um intuito propositalmente dialógico no núcleo do pensamento cinematográfico de Sganzerla. Vale lembrar que a mixagem implica interferências e modificações, o que significa abrir para a transposição criadora tal como a inversão cronotópica já referida, espaço de manifestação das próprias contradições do Bandido recriadas por meio de efeitos dramatúrgicos audiovisuais.

O que é a posição de Sganzerla, quer seja crítico ou criador, senão a de um elo que, como um prisma, estabelece cadeias de relações com a história do cinema e, consciente de sua posição, tem como pretensão uma continuidade na construção de tal história, abrindo-se também, por sua vez, ao diálogo com o futuro? 0 procedimento indutivo do "filme-soma" tenta produzir uma obra que funcione como um "filme-síntese", que aponte encaminhamentos para uma cinematografia vindoura. Mais do que eventuais relações de correspondência intertextual esboçadas no manifesto, cabe notar como Sganzerla produz nele uma visada dialógica para a História cinematográfica em sua busca por interlocuções continuadas com as múltiplas vozes que a constroem e a construirão.

No prosseguimento do manifesto, vários nomes de realizadores são mencionados, alguns mais e outros menos óbvios enquanto influência e diálogo em $O$ Bandido. Ao longo do 
texto, são citados, entre outros, Jean-Luc Godard (1930), Orson Welles (1915-1985) e José Mojica Marins (1936) com sua "poesia furiosa dos atores do Brás" (2005, p. 40). É interessante pensar nessa listagem de influências, algumas delas meramente afetivas, por um viés que observe esses nomes pelo que possuem de mais ou menos óbvio na construção de uma conversa declarada dentro do filme de 1968. E, a partir disso, perceber o quanto a dimensão interlocutória de sua crítica acarretou na emergência de vozes em sua criação pela via da exploração de gêneros, de sistemas de ideias e de influências deglutidas originando no contexto criativo do filme de 1968 uma estética da avacalhação que visava sintetizar o cinema feito até então.

Quanto a Mojica, sua aparição no filme surge antes como presença que compõe um imaginário e um método possível de cinema subdesenvolvido, isto é, da possibilidade de trabalhar com a linguagem fílmica no âmbito da escassez de recursos. Já com relação a Godard e Welles, cabe notar a presença de ambos como pontos de contato sganzerlianos privilegiados com relação à história do cinema desde as críticas do Estadão até a composição do "filme de cinema". Ou seja, tendo a dicotomia corpo e alma como seu ponto de partida, os elementos essenciais de sua ontologia cinematográfica se fundamentam a partir do contato do duplo crítico-cinéfilo com a produção de ambos. Se Charles Foster Kane representa, de acordo com seus escritos, o "herói fechado" por excelência, indecifrável pelo aparato que capta o visível, o uso da câmera por Godard seria o mais analisado nos textos sganzerlianos sobre a "câmera cínica". "Câmera cínica" e "herói fechado" são dois conceitos fundamentais na produção crítica de Sganzerla e em sua busca criativa posterior de uma proposição para o impasse entre corpo e alma. Para ele, no contexto do cinema moderno e, sobretudo, na vertente do corpo, a câmera cinematográfica e o herói por ela registrado teriam uma relativa independência, um relativo desinteresse mútuo. Se essa câmera observa as situações dramáticas à altura de um olho humano - e, enquanto tal, potencialmente falível, porque incompleto -, o herói fechado seria despido de um interior, ficaria restrito ao que pode ser captado pelo aparato técnico. Câmera e herói, assim, são mutuamente dependentes em sua relativa independência. No caso de Kane, sua interioridade indevassável seria colocada em xeque e promoveria a emergência de uma cadeia de discursos em torno de seu nome, sobre quem ele de fato seria e o que ele pensava ou sentia.

É notória, nesse sentido, a cine-filiação crítica e criativa de Sganzerla com certo encaminhamento inventivo proposto por tais realizadores. Algo que se torna perceptível na construção do personagem Luz Vermelha como alguém cujas crises de identidade o levavam 
a cair num jogo interior de contradições, muitas vezes causadas pelo excesso de informação, o que contribuía para a criação de situações caóticas. Por exemplo, na sequência em que está na praia (figura 3), com Janete Jane, ele diz a ela num determinado momento: "Tudo bem, graças a Deus. Deus uma ova. Deus não existe". Assim, numa única enunciação sonora, duas entoações radicalmente divergentes: uma que tende à euforia e outra totalmente disfórica, o que marca também uma mudança de tom com relação ao conjunto entoativo de suas enunciações no filme, com ênfase nos tons baixos, quase sussurrantes. A câmera cínica do brasileiro, como era de se esperar, circunda o Bandido e Jane, não de um ponto de vista ideal, mas à procura do melhor ângulo possível.

Figura 3 - Fotograma de 0 Bandido da Luz Vermelha, aos 52 minutos.

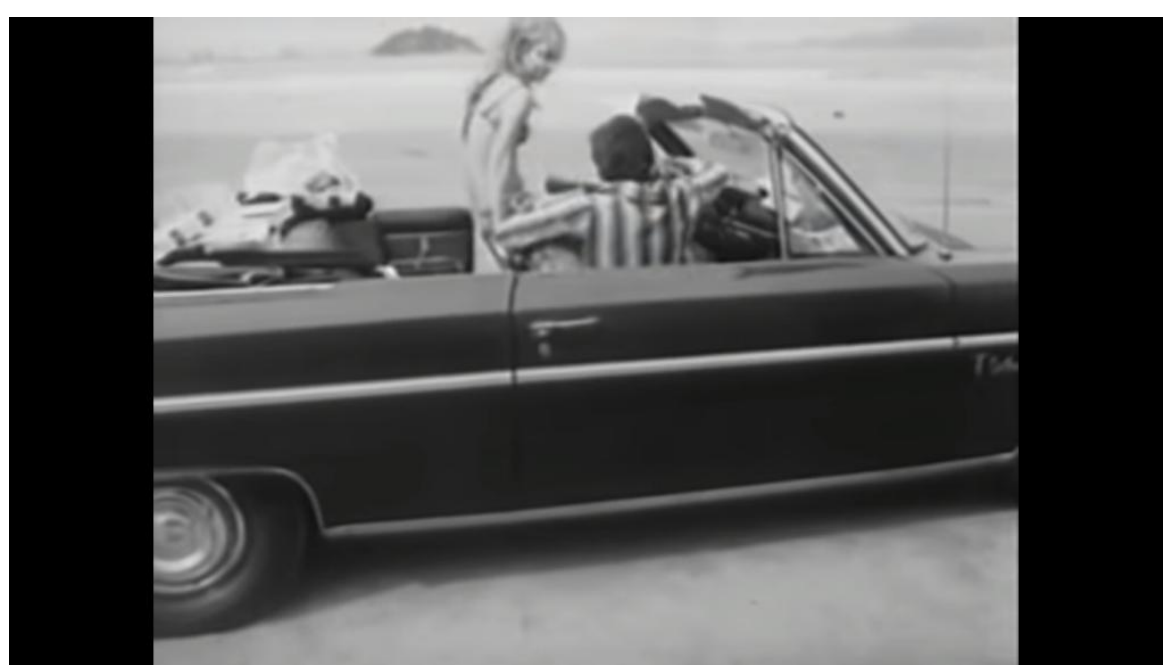

Fonte: reprodução de $O$ Bandido da Luz Vermelha (1968).

A inexistência de Deus, nesse caso, pode ser lida também no contexto do pensamento crítico de Sganzerla, particularmente, em sua leitura da modernidade cinematográfica. Em seus escritos, o chamado cinema clássico se caracteriza como aquele que busca certa visão divina na construção de sua decupagem, de modo a focalizar os acontecimentos por meio da onipresença da câmera, que a tudo olha e observa, de uma posição elevada, assim delineando o enredo. 0 cinema moderno, por sua vez, Sganzerla caracteriza como o cinema que vai de encontro com os acontecimentos das ruas, observando, como foi dito, as situações dramáticas à altura de um simples olhar, o que garantiria à imagem certa falibilidade e mesmo alguma independência eventual entre 
equipamento de registro e ação. No discurso do personagem, portanto, está implícita a discussão iniciada nos paineis.

\section{Polifonia ante a saturação dos discursos interiores e dos signos do espaço}

Buscar "o melhor ângulo possível" (SGANZERLA, 2001, p. 18) traduziu todo o trabalho não apenas da câmera nos filmes mas também da postura crítica do cineasta em sua necessidade de construir ações integradoras, relativizadas e com direito a dúvidas. Se os filmes de Sganzerla resultam dos ângulos que presidem sua realização, não é difícil de inferir que o cinema assim construído leva o processo dialógico de sua trama poética ao estado de interação polifônica com seu próprio processo criativo e consequentemente, com seus espectadores. Por que se movimenta em busca do melhor ângulo, a câmera dialoga não apenas com as situações mas cria contrapontos aos personagens, contrariando e desviando o vetor do que se afirma com palavras, olhares, gestos que vêm do interior. Como afirmava o cineasta: "A alma e os sentimentos não são o princípio enfim de tudo, inclusive da sétima arte: são um dos aspectos da existência, do mundo, do cinema." (SGANZERLA, 2001, p. 80)

Ver e alcançar com seu movimento e variação a variedade das coisas do mundo em “ângulos, panorâmicas e planos-sequências” (SGANZERLA, 2001, p. 76) não só conjugam a tônica do olhar que constrói seus filmes mas, sobretudo, o afastam de fazer cinema como literatura, de olho na alma dos personagens. Por se ocupar do exercício do ver, o cineasta se aproxima muito mais do jornalista que investiga ângulos dos acontecimentos, tal como confessa na entrevista a 0 Pasquim: "Eu uso cinema de uma forma jornalística. Eu também fui jornalista. Fui até repórter policial. Eu acho que o jornal dá uma visão diferente." (0 PASQUIM, 1970). Em ambos os casos, o olhar não é o que fixa, mas o que percorre, atravessa, refrata, extravasa, encontra ou se choca com extensões nem sempre contíguas. Neste movimento, o olhar assume a condição de um discurso polifônico, múltiplo, dinâmico, de confrontos.

Paradoxalmente, enquanto o cineasta afirma estar afastado da literatura, o modus operandi de sua poiesis está muito próxima de grandes personagens do romancista russo Fiódor Dostoiévski, também jornalista policial por profissão. Queira ou não, o personagem de Luz Vermelha pode ter escapado de ser um "filósofo da tela" (SGANZERLA, 2001, p. 78), 
contudo, não fugiu ao seu destino de ideólogo em conflito com seu próprio discurso, com seu próprio deslocamento. Com isso, não é de toda literatura que o pensamento do cineasta mantém distanciamento. Afinal, em nenhum momento de sua filmografia Sganzerla virou as costas para o universo interior das personagens, fonte inesgotável de muitos de seus enigmas. É nesse conjunto de procedimentos, que muitas vezes são traduzidos como procedimentos de meros filmecos, que se manifesta a trama polifônica que atravessa e supera gêneros, discursos, enunciados para alcançar outras regiões de sentido a que só o cinema pode levar.

Diríamos, pois, que a presença de uma variedade de textos dentro de $O$ Bandido, em seu procedimento declarado de "fusão e mixagem" de gêneros, e em suas vastas teias de relações que remetem à produção escrita prévia ao seu lançamento, evidencia o potencial polifônico da obra. Evidentemente que a aproximação aqui delineada se fundamenta no conceito de polifonia remete ao clássico estudo de Bakhtin acerca dos Problemas da poética de Dostoiévski, particularmente quando o teórico da dialogia pondera:

\begin{abstract}
Ao tomarmos conhecimento da vasta literatura sobre Dostoiévski, temos a impressão de tratar-se não de um autor e artista, que escrevia romances e novelas, mas de toda uma série de discursos filosóficos de vários autores e pensadores: Raskólnikov, Míchkin, Stavróguin, Ivan Karamázov, o Grande Inquisidor e outros. Para o pensamento crítico-literário, a obra de Dostoiévski se decompôs em várias teorias filosóficas autônomas mutuamente contraditórias, que são defendidas pelos heróis dostoievskianos. Entre elas as concepções filosóficas do próprio autor nem de longe figuram em primeiro lugar. Para alguns pesquisadores, a voz de Dostoiévski se confunde com a voz desses e daqueles heróis, para outros, é uma síntese peculiar de todas essas vozes ideológicas, para terceiros, aquela é simplesmente abafada por estas. Polemiza-se com os heróis, aprende-se com os heróis, tenta-se desenvolver suas concepções até fazêlas chegar a um sistema acabado. 0 herói tem competência ideológica e independência, é interpretado como autor de sua concepção filosófica própria e plena e não como objeto da visão artística final do autor. Para a consciência dos críticos, o valor direto e pleno das palavras do herói desfaz o plano monológico e provoca resposta imediata, como se o herói não fosse objeto da palavra do autor mas veículo de sua própria palavra, dotado de valor e poder plenos.(BAKHTIN, 2013, p. 16).
\end{abstract}

A diversidade de personagens que se debatem com seu próprio discurso e com o outro chegou às últimas consequências na novela de Dostoiévski 0 duplo, quando Goliádkin tem um sósia projetado de seu próprio ser e com ele passa a conviver numa tensão 
permanente. Ainda que Dostoiévski esteja escrevendo literatura, a orientação de todo o seu trabalho criativo é conferir forma espacial às personagens de modo a alcançar os diversos ângulos de seu comportamento (MACHADO, 2017). Eis o ponto de uma aproximação com Luz Vermelha, personagem cuja dinâmica espacial de seu próprio corpo não se pode negar, em complementação às diversas espacialidades de convivência com seus "duplos" que não são projetados em outros seres, mas são concretizados em ações, discursos e na sua relação com os espaços.

De toda a "série de discursos" que transparecem de modo declarado ou implícito na composição crítico-criativa que é $O$ Bandido, prosseguindo no estudo do exercício sganzerliano de pensar o artístico - e por que, não, o mundo? - como encontro de repertórios diversos em diálogo, cabe agora examinar como Luz Vermelha se coloca em relação ao outro. Não sem surpresas se encontra uma personagem cuja persona se revela e se esconde na saturação de signos da cidade, na construção mítica de si mesmo por meio das narrativas entre narrativas em torno de seu nome, nos jogos contraditórios de seus próprios diálogos interiores e também em suas interlocuções com os demais personagens. Se o aspecto polifônico nasce do prosseguimento implícito da metalinguagem iniciada nos paineis, no âmbito da diegese ele se encontra no cerne da experiência do espaço urbano.

Prosseguindo pela via sugerida pela citação acima, é notória a construção de um universo fundado no tensionamento ideológico presente nas vozes de Luz, Janete Jane, Delegado Cabeção, J.B. da Silva e dos narradores radiofônicos; as frases de efeito produzem o conflito dicotômico que marca a produção. A independência das vozes e dos ideais inerentes a esses personagens - cujas trajetórias são construídas, evidentemente, em torno da mítica que ronda a existência e a atividade criminal do Bandido - se fundam na relativa independência entre a natureza episódica das situações ante o desfecho conclusivo prenunciado desde o primeiro dos muitos "fracassei, eu sei que fracassei", de Luz. No caso deste, sua independência fundada no elemento contraditório acerca de seu edifício identitário chega inclusive a se chocar com a figura do diretor da obra, quando aos 39 minutos de filme ele picha em uma parede o nome da cidade natal de Sganzerla - Joaçaba (figura 4), município do estado de Santa Catarina. 
Figura 4 -Fotograma de 0 Bandido da Luz Vermelha, aos 39 minutos

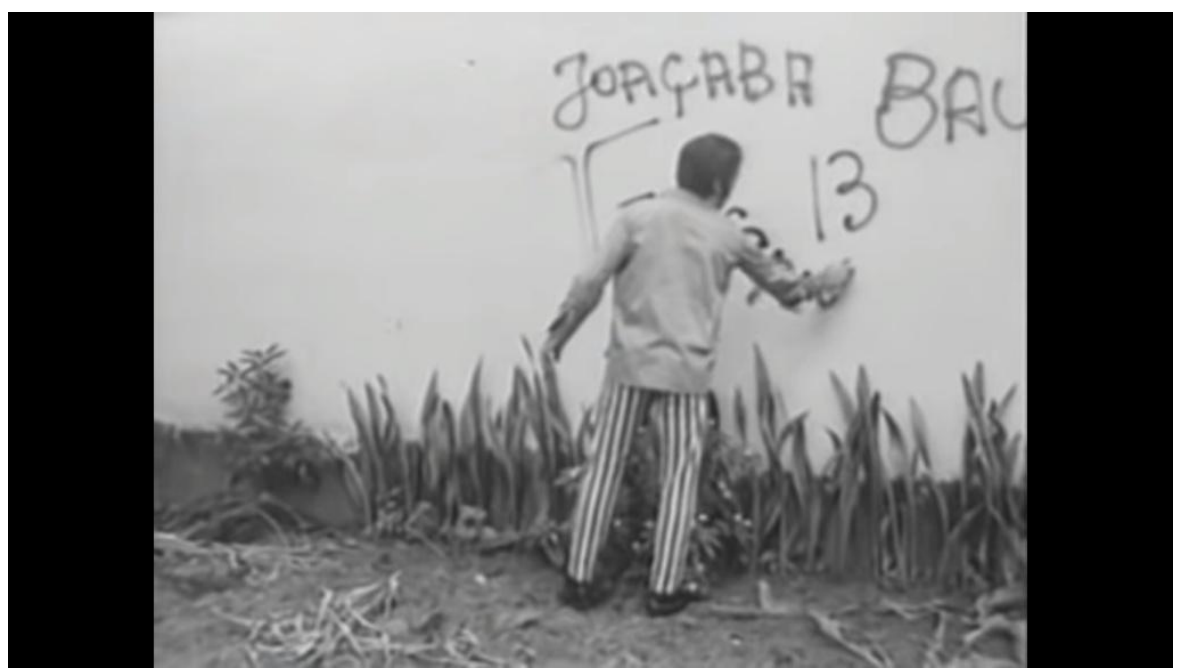

Fonte: reprodução de O Bandido da Luz Vermelha (1968).

Se a voz de Luz Vermelha, seja aquela proferida ou aquela que emana como discurso interior, é exemplar de sua independência na estrutura da obra, a ponto de extravasá-la, o mesmo vale para o segmento que introduz em cena o Delegado Cabeção. Nele, o personagem aponta para um quadro na parede de uma cena de crime, e diz: "Arte moderna. É o que sempre digo: coisa de depravado. Lixo. (...) Quanto mais podre, mais caro. Por mim, eu mandava juntar tudo isso e... botar fogo! (...)"; trata-se de uma oposição clara à própria fundação estética que rege a obra da qual ele é membro integrante. 0 anti-discurso do delegado evoca uma das proposições mais radicais do teórico-cineasta em seu entendimento de que,

No cinema como política, moral, estética, a revolução formal significa simplesmente opção diante da certeza e o talvez. Em sua passagem ao relativo, o cinema atual propõe uma solução dialética: conflitar os dois métodos de captação da realidade (Destino versus História), sobrepor o destino individual com o coletivo, comunicar a mente com a massa. (SGANZERLA, 2001, p. 23)

O confronto dialógico com discursos ideológicos de matiz conservadorista desloca o foco do próprio discurso que não deixa de refratar o próprio discurso do cineasta. Afinal, é 
no nível do ideologema que todas as refrações podem ser mais explicitamente cogitadas visto que não se trata de discurso manifesto.

Quanto ao Bandido, na pergunta "um gênio ou uma besta?", que aparece pela primeira vez no mesmo letreiro onde se lê a epígrafe "filme de cinema", observa-se o mesmo deslocamento, a mesma refração: a pergunta transcrita em luz de neon se refere tanto ao personagem Bandido quanto do diretor do filme. Contudo, de certa forma a questão pode inclusive não se restringir a esses dois caminhos interpretativos, uma vez que inicia uma série de pares de oposições dialéticas que permearão a obra, instalando a dúvida e alimentando o paradoxo. Dúvidas ou embates ideológicos de repertórios tão contrários quanto estreitos só contribuem para a construção da relatividade que insufla uma atmosfera de um terceiro mundo em ebulição. A saturação de signos, intra ou extra diegese, opera de maneira a situar o espaço urbano como território de troca dialógica explosiva. Corpo ou alma, masculino (Luz) ou feminino (Janete Jane), "sou o maior" ou "tentei me matar com a tinta a óleo", entre outros impasses, constroem a atmosfera de embates de ideias opostas em tensão.

Mesmo os discursos interiores de Luz não se colocam em posição estritamente monológica; em outras palavras, há uma consciência interlocutória em sua verbalidade interna explorada na radicalidade de uma dramaturgia eminentemente audiovisual, como examinada em outros estudos (BERNARDET, 1990; 2010; MACHADO, 2018). Para além das eventuais ruminações interiores que se dirigem a terceiros - à imprensa, à polícia, aos bandidos de todo o Brasil, à Mão Negra -, Luz entra no jogo do excesso informativo dos recortes de jornais e da conversa dos narradores radiofônicos; quanto maiores os detalhes da construção narrativa de seu passado, maior o aspecto de dúvida quanto a quem ele de fato é. Nos fragmentos de sua trajetória, a disparidade das informações - tais como o nascimento na favela do Tatuapé, o passado em "Assunción, Paraguai", o título de campeão de tiro ao alvo em Mato Grosso, entre outras - promove uma falta de coesão, que é alimentada por ele mesmo em diálogo com as muitas narrativas em torno de sua atividade criminosa. A crise de identidade de traços existencialistas exemplifica o herói fechado que vive por entre impasses, mas busca uma saída, tal como formulado pelo Sganzerla crítico, uma vez que, contraditório e indecifrável, tem sua interioridade refratária à própria câmera. Em outro sentido, sua crise de identidade também contribui para a inserção do próprio herói num contexto polifônico que, em alguma medida, dilata a relação entre o indivíduo e o coletivo. 
Nesse sentido, observa-se que, numa sequência inicial do filme, ressoa uma frase dita pelo Bandido - "sou um dos bandidos da Luz Vermelha" -, declaração que ganha importância conforme a natureza episódica vai dando espaço a um final conclusivo, exemplificado em outra declaração - "fracassei, mas vem outro". Não deixa de projetar em outros seres, outros espaços, a possibilidade de existirem outros bandidos da Luz Vermelha.

A apropriação do cognome de João Acácio, Bandido da Luz Vermelha, e sua transformação em nome artístico, título do filme e nome do personagem, se relaciona não apenas a um tensionamento entre ficção e documento, mas também, e em especial, a essa tensão entre individual e coletivo numa existência de caráter dialógico-polifônico, cujas histórias se configuram não como cadeias de caráter lógico e retilíneo, mas como fragmentos de narrativas entre narrativas. Com isso, o caráter polifônico constitui uma trama em que a voz do Bandido funciona como uma caixa ressonante de diálogos interiores marcados de tensionamentos, de gritos de revolta, de desafios ao status quo social e, sobretudo, à mediocridade de discursos aparentes, aqueles tão eloquentemente enunciados pela sonoplastia das vozes que formam o eco contra o qual Luz Vermelha emite sua dissonância.

Na cena anterior à sequência do suicídio de Luz, o personagem sai de uma sessão de cinema e se põe a caminhar pelas ruas da capital paulista. No curto caminho que o leva até uma banca de revistas, nos cartazes que estão expostos do lado de fora da sala de exibição pode-se ler, primeiro, "O signo da morte", título de uma obra de 1939 dirigida por Chano Urueta (1904-1979); no seguinte, lê-se "Só contra todos", faroeste de 1965 com direção de Edoardo Mulargia (1925-2005) e José Antonio de La Loma (1924-2004). Os cartazes trazem um novo prenúncio do final, que já vinha sendo reiterado sutilmente. Assim, na sequência seguinte, Luz irá se encarregar de sua própria eletrocussão antes de ser capturado pela polícia. É, porém, um jornal exposto na banca que chama a atenção do personagem: uma consideração do indivíduo ante a criação mítica em torno de sua trajetória. Nele, ele vê um retrato falado de si mesmo e lê a manchete, escrita em letras garrafais e sublinhada: ESTE HOMEM É O PERIGOSO BANDIDO DA LUZ VERMELHA (figura 4). Ao que ele retruca: "Até que tá bacana. Acho que agora isso tudo vai acabar". No olhar de Luz para a versão desenhada e impressa de si mesmo não há perplexidade; antes, há um reconhecimento de si mesmo como ser polifonicamente refratado. Esse retrato, portanto, como signo alheio, traduz para ele sua própria existência de modo mais apropriado do que os variados objetos que, antes da chegada dos policiais, são retirados de uma mala - na qual se lê um "Eu" em 
seu interior - antes de serem atirados num rio. Novamente é destacado o cartaz de "O signo da morte" (figuras 5 e 6), o que enfatiza um desfecho iminente. 0 vendedor de jornais o reconhece e cogita denunciá-lo à polícia.

Figuras 5 e 6 - Fotogramas de 0 Bandido da Luz Vermelha, aos 83 minutos.
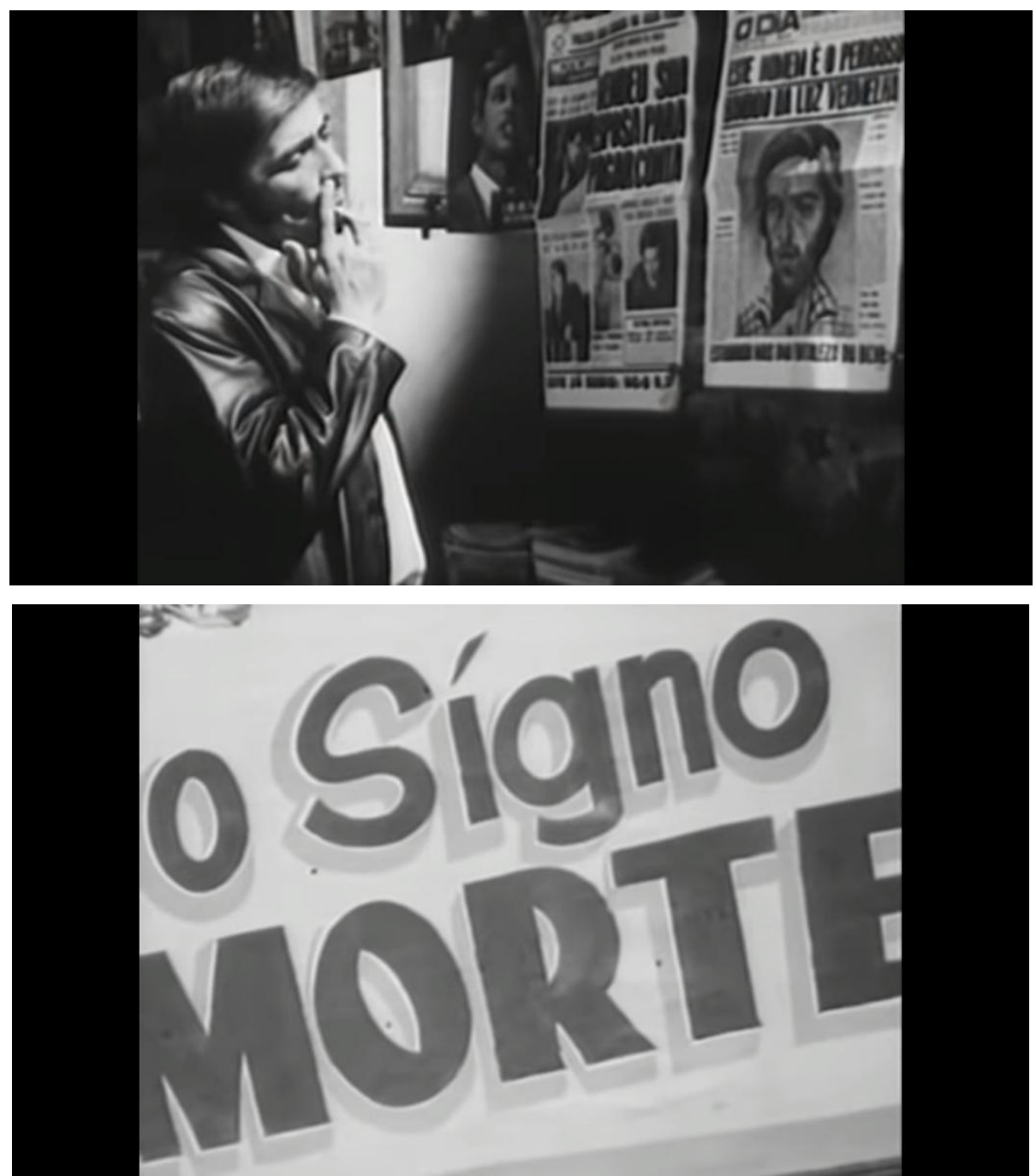

Fonte: reprodução de O Bandido da Luz Vermelha (1968).

Os garranchos rudimentares e pouco inteligíveis que Luz escreve na parede evidenciam os registros de sua trajetória em sua própria linguagem; por sua vez, os jornais, os radialistas e os pontos de vista alheios traduzem a existência do criminoso em outros signos, tornando o indivíduo refém de um imaginário do qual não tem controle.

Quando o Bandido é enfim encontrado, já eletrocutado, a distinção entre Luz-sujeito e Luz-signo é tornada exemplar na reação de um dos policiais, que diz, pausadamente: "não... 
não pode... pra mim é o cara errado". Eis, portanto, o descolamento entre o indivíduo e a construção sígnica que traduziu sua trajetória em meios diversos. Luz Vermelha, como herói fechado, traduz filmicamente, nos embates de suas crises existenciais - seja como interioridade contraditória, seja como a negação da materialidade do "eu" que é arremessada no rio - não apenas a oposição entre os cinemas do corpo e da alma, mas também o posicionamento sganzerliano ante as vozes da história cinematográfica em sua proposição de um filme-síntese.

\section{Conclusão}

A fundação dos conflitos brotada dos embates ideológicos promovidos pelos textos diversos e pelas relações dialógicas em $O$ Bandido da Luz Vermelha traz consigo a característica primordial da crítica sganzerliana que aqui entendemos a partir do fenômeno da refração. Entendida como condição semiótica do signo de transformar-se e assumir configurações que mantem a contiguidade sem necessariamente garantir a equivalência, refração aponta para a prática dialógica de expandir-se para novas prospecções.

A expressão filme de cinema, que no início do filme $O$ Bandido da Luz Vermelha surge como uma epígrafe, pode ser pensada como a máxima sobre a qual se ergue o cinema moderno que, no caso de Sganzerla, se baseia no exercício crítico de uma prática cinematográfica que pensa em sua própria construção e deve sua existência aos diálogos, às transformações e refrações audiovisuais com os filmes que lhe pareciam dignos desta denominação. Se, por um lado, o filme de cinema torna visível um estado de consciência sobre o corpo estético que o constitui - estético no sentido de consciência dos procedimentos construtivos de sua poiesis - por outro, abre o debate sobre as bases do cinema moderno. Em ambos os casos há que se ponderar sobre relações de uma prática experimental com a reflexão crítico-teórica no âmbito de uma historiografia cinematográfica que atua em contextos da produção cinematográfica brasileira e internacional. Estão em jogo diferentes estados de consciência. Com isso, a própria noção de filmecos merece ser reconfigurada.

Do ponto de vista do processo de experimentação das ideias audiovisuais, os filmecos concentram o laboratório experimental de produção de curtas-metragens, experimentos audiovisuais, exercícios com eventos sonoros, enfim, ideias fílmicas que 
sustentam a criação e fundamentam a crítica no exercício teórico do cineasta. A renovação da linguagem do cinema depende fundamentalmente da produção subdesenvolvida de baixo orçamento, o que levou Sganzerla a conferir a tal condição a natureza e a vocação de seus filmecos e, consequentemente, de seus filmes de cinema. $O$ Bandido da Luz Vermelha se tornou o marco emblemático de toda esta reconfiguração do cinema moderno e da própria cultura audiovisual que se expandiu a partir dele. Sganzerla integra o circuito dos cineastas que não hesitaram em lutar para construção de um novo repertório de formas audiovisuais e de poéticas que questionam modelos convencionais dominantes.

Evidentemente que uma prática crítico-criativa desta natureza revela que o crítico Sganzerla tende a enfatizar o processo poético da criação, contudo dele não está apartado a criação no âmbito de uma estética dialógica, sobretudo aquela que valoriza a natureza semiótica da audiovisualidade - quer isso se refira ao acontecimento do processo produtivo, quer se refira à própria existência de uma obra, jamais isolados dos contextos históricos que a antecederam e que a sucederão, em sua leitura. Tal reconhecimento torna-se ainda mais significativo na medida em que o percebemos tanto em sua escrita crítica quanto como uma formulação implícita em forma fílmica, conforme examinado na análise da película de 1968.

É importante salientar como as características posteriores do Sganzerla realizador, no que diz respeito a seu encontro e abertura a outras textualidades já se encontram no Bandido: está nele o embrião de sua relação com a liberdade criadora do ator ante a câmera, que ganha um primeiro plano, em especial, nos anos 1970; também, o uso do arquivo recontextualizado, que ainda não ganha, aqui, contornos de reescrita da história, provocada e provocativa, como no projeto sobre Welles. Tais considerações demonstram como o estudo da estreia sganzerliana em longas-metragens à luz de seus escritos em jornais não apenas apresenta contribuições a um exame para o seu sistema crítico-criativo, como solidifica o olhar para sua obra do ponto de vista da sistemicidade contida em seus exercícios de se colocar em dinâmica relacional.

Com isso, a observação, na crítica, de tendências opostas que apresentam a necessidade de um cinema que as sintetize, funciona no ideário estético-poético de Sganzerla como um gérmen de sua pretensão de contribuições formais à grande teia da história fílmica, fundadora do cinema moderno a que ele se reporta inúmeras vezes. Se a orientação dialética do cineasta o leva a um cinema de exceção, ou do "corpo mais alma", então não é difícil divisar nesta tendência o caminho construtivo do autêntico "filme de cinema" na refração de procedimentos de renovação. 


\section{Referências}

AUMONT, Jaques. As teorias dos cineastas. Campinas: Papirus, 2012.

BAKHTIN, Mikhail. Os gêneros do discurso. São Paulo: Editora 34, 2016.

BAKHTIN, Mikhail. Problemas da poética de Dostoiévski. Rio de Janeiros: Grupo Gen, Editora Forense, 2013.

BERNADET, Jean-Claude. 0 vôo dos anjos. São Paulo: Brasiliense, 1990.

BERNADET, Jean-Claude. Universo sonoro. In: Ocupação Rogério Sganzerla. São Paulo: Itaú Cultural, 2010. Vídeo: Youtube. Disponível em: https://www.youtube.com/watch?v=JDYPYV14LCw. Acesso em: 4 jan. 2017.

MACHADO, Irene. Dramaturgia sonoro-acústica em espaços cinemáticos. Revista Famecos, Porto Alegre, v. 25, p. 1-18, 2018.

MACHADO, Irene. Forma espacial da personagem como acontecimento estético cronotopicamente configurado. Bakhtiniana, Revista de Estudos do Discurso, São Paulo, 2017, vol.12, n.2, p.79-105.

NORONHA, Danielle. Edgar Brasil: o patrono dos diretores de fotografia brasileiros. Associação Brasileira de Cinematografia, 2017. Disponível em: \&lt;https://abcine.org.br/site/edgar-brasil-o-patrono-dos-diretores-de-fotografiabrasileiros/\&gt;. Acesso em: 30 abr. 2019.

O BANDIDO da Luz Vermelha. Direção: Rogério Sganzerla. Brasil: Urano Filmes, 1968. 92 $\min$.

O PASQUIM. Helena - a mulher de todos - e o seu homem. Rio de Janeiro, n. 33, 5-11 fevereiro de 1970. Disponível em: www.contracampo.com.br/27/frames/sganpasquim.htm. Acesso: 23/04/2019.

SGANZERLA, Rogério. Por um cinema sem limite. Rio de Janeiro: Azougue, 2001.

SGANZERLA, Rogério. Tudo é Brasil. Joinville: Editora Letradágua, 2005.

XAVIER, Ismail. Cinema brasileiro moderno. São Paulo: Paz e Terra, 2001.

\section{Financiamento}

Pesquisa financiada por CNPQ.

O presente trabalho foi realizado com apoio da Coordenação de Aperfeiçoamento de

Pessoal de Nível Superior - Brasil (CAPES) - Código de Financiamento 001. 


\title{
Refractions of the movie film concept in Rogério Sganzerla's work
}

\begin{abstract}
The article examines the critical-creative thinking of the filmmaker Rogério Sganzerla (1946-2004), crossing his theoretical production with constructive procedures of The Red Light Bandit (1968), his debut in the direction of feature films. Our hypothesis is that the look at Sganzerla's system of production reveals, beyond an application of its critical formulations in its filmic work, the way in which his thoughts are configured in order to consider the dialogue - both in critical texts and in the context of diegesis - as an implicit element in the organization of a theoretical-critical-creative system.
\end{abstract}

\section{Keywords}

Rogério Sganzerla. Brazilian cinema. Film critic. Dialogism. Metalanguage.

Recebido em 04/05/2019

Aceito em 07/06/2019 